\title{
Introduction to the Russo-Japanese revolution in stabilometry.
}

\author{
Pierre-Marie Gagey ${ }^{1}$
}

\section{ABSTRACT}

We knew that the postural system was concerned with the venous return circulation and the stabilization of the body, but we did not know that the stabilometric signal was modified by the interference of these two functions. A new signal analysis is being made.

Keywords: Posturology; Stabilometry; Stability; Circulation; Signal analysis;

\section{BACKGROUND}

Since the studies by Inamura et al. were published ${ }^{(1-3)}$, we know that the postural system is also concerned with control of the venous return circulation (Figure 1).

The discovery of Inamura et al. did not change our approach to stabilometry, which we pursued it from a purely mechanical perspective, in relationship to the subject's stability, without being able to determine how to integrate this discovery into our reflections. At that time, venous return was not a focus of our interests; we were trying to figure out how to calculate the position of the center of gravity from the position of the center of pressure, which mobilized a large number of teams for decades until in 2016 ${ }^{(4-15)}$. Recently, V. Usachev and V. Belyaev took on long-term stabilometric recordings (7 minutes).
They showed migrations, about every minute, of the average point around which the center of pressure stabilizes during this minute (Figure 2).

These displacements of the pressure zones on the plantar sole, and, consequently, on Lejars' venous sole ${ }^{(17,18)}$ evoke phenomena implicated in venous return, which remain to be confirmed. But, on the other hand, the migrations, every minute, of the mean point around which the center of pressure stabilizes during that minute, have immediate consequences on our conception of stabilometric signal analysis. We can no longer speak of $X$-means and $Y$-means, except in the mode of approximate values because there are indeed a series of different $X$-means and $Y$-means, and the $X$-mean and $Y$-mean
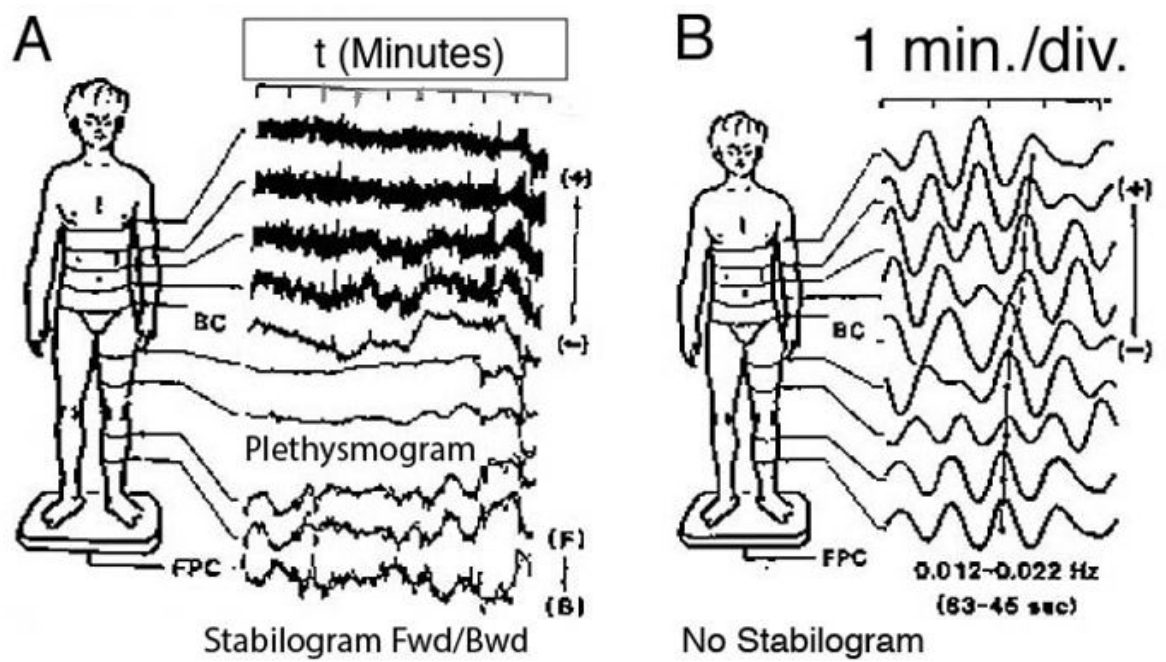

Figure 1 - Stabilogram/Plethysmogram Comparison; Inamura's “one-minute wave". Note: A: Nine 1-minute recordings. Only the forward/backward stabilogram is shown, in phase opposition to the contours of the leg. B: Enlargement of a part of A to show the continuity of the volume wave between the leg and thorax. This subject's wave frequency is between 0.012 and $0.022 \mathrm{~Hz}$. (Figure reworked after Inamura et al., 1990). 


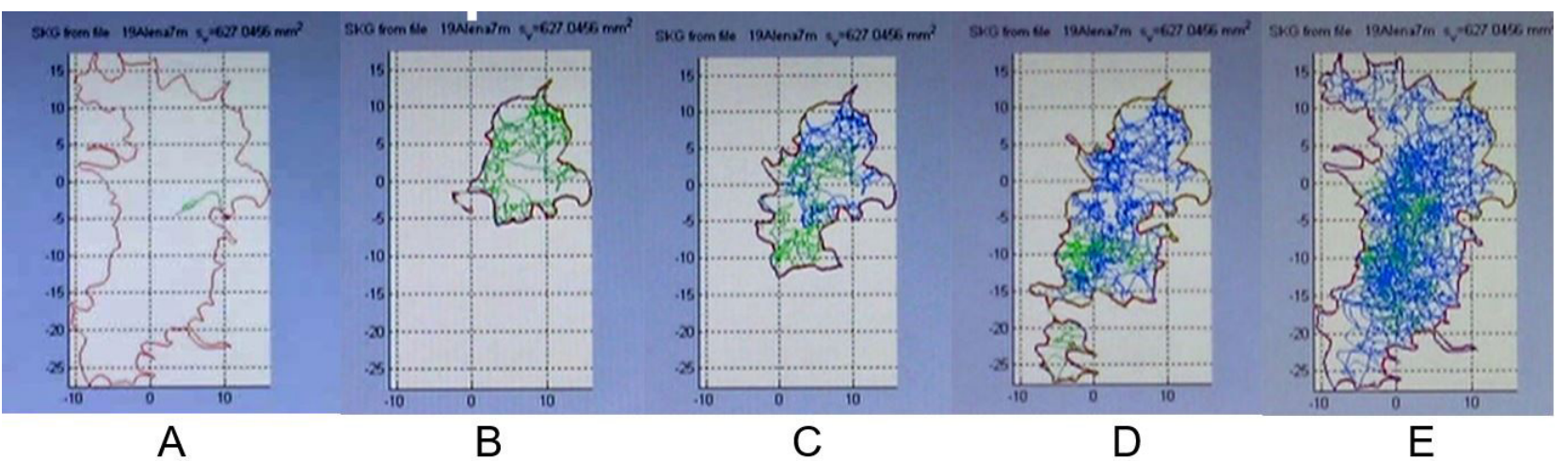

Figure 2 - One-minute movement summaries of a 7-minute stabilometric recording

Note: (From the video made by V. Belyaev $\left.{ }^{(16)}\right)$. A: Contour of the surface that will be occupied during the recording session by the pressure center displacements by the end of the 7-minute recording. (To give a general overview of the framework of these movements). B: Tracing of the summarized movement of the stabilization zone of the center of pressure during minute 1 (Freeze frame at the end of the first minute). C: Tracing of the summarized movement of the stabilization zone of the center of pressure during minute 2 (Freeze frame at the end of the second minute). D: Tracing of the summarized movement of the stabilization zone of the center of pressure during minute 4: note the clear shift from the preceding zones (Freeze frame at the end of the fourth minute). E: Global summary of the 7-minute recording of the final frozen frame of the video.

that are computed on short recordings represent only singular elements of this series. According to the video images, the difference would be more important between the $Y$-means than between the $X$-means, which is in accordance with the statistically known extents of the deviations of the $Y$-means, $48 \mathrm{~cm}$, and of the $X$-means, $2 \mathrm{~cm}$, described in Normes $85^{(19)}$.

We can no longer speak of measuring stability, since there is no longer ONE mean equilibrium position; remember that stability is the property of a body that automatically returns to the vicinity of ITS equilibrium position, when it is displaced from it.

\section{CAN WE STILL TALK ABOUT "STABILOMETRY"?}

The Russians and the Japanese already proposed "stabilometric" parameters that take into account the complexity of the signal coming from the force platforms, because that signal accounts for stability phenomena, along with hemodynamic phenomena ${ }^{(20)}$.

\section{CONFLICT OF INTERESTING}

The author declare no conflict of interest.

\section{REFERENCES}

1. Inamura $\mathrm{K}$, Mano $\mathrm{T}$, Iwaze $\mathrm{S}$, editors. One minute wave of body sway related to muscle pumping during static standing in human. ISPGR; 1990; München: Georg Thieme (Stuttgart).

2. Inamura $\mathrm{K}, \mathrm{Mano} \mathrm{Y}$, Iwaze $\mathrm{S}$, Yamamoto $\mathrm{K}$, editors. Changes in functioning mechanisms of one minute wave in body fluid volume during head-up and head-down tiltings in humans. Posture and gait: control mechanisms; 1992; Portland: University of Oregon Books.

3. Inamura K, Mano T, Iwaze S. Role of postural sway as a compensatory mechanism for gravitational stress on the cardiovascular system. Gait Posture. 1999; 9 (suppl. 1):S5.

4. Spaepen A, Vranken M, Willems E. Comparison of the movements of the center of gravity and of the center of pressure in stabilometric studies. Agressologie. 1977;18(2):109-13.
5. Shimba T. An estimation of center of gravity from force platform data. J Biomech. 1984;17(1):53-60

6. Levine $\mathrm{O}, \mathrm{J} \mathrm{M}$. An iterative model for the estimation of the trajectory of the center of gravity from bilateral reactive force measurements in standing sway. Gait Posture. 1996;4:89-99.

7. King D, Zatsiorsky V. Extracting gravity line displacement from stabilographic recordings. Gait \& Posture. 1997;6(1):27-38.

8. Caron J, Faure B, Brenière Y. Estimating the centre of gravity of the body on the basis of the centre of pressure in standing posture. J Biomech. 1997:11-12:1169-71.

9. Brenière Y. Why we walk the way we do? J Motor Behavior. 1996;28(4):291-8.

10. Zatsiorsky V, D K. An algorithm for determining gravity line location from posturographic recordings. J Biomechanics. 1998;31:161-4.

11. Morasso P, Spada G, Capra R. Computing the COM from the COP in postural sway movements. Human Movement Science. 1999;18:759-67.

12. Barbier F, Allard P, Guelton K, Colobert B, Godillon-Maquinghen A. Estimation of the 3-D center of mass excursion from force-plate data during standing. IEEE Trans Neural Syst Rehabil Eng. 2003;11(1):31-7.

13. Hugon $M$, Ouaknine. $M$, editors. L'équilibration posturale se réalise par relaxation entretenue de commandes automatisées. Efficience et Déficiences du Contrôle Postural; 2004; Dijon.

14. Gagey B, Bourdeaux O, Gagey P. From the center of pressure to the center of gravity, a new algorithm for a step forward in stabilometry. MTPRehab Journal. 2015;13:264-70.

15. Gagey B. Solution théorique et calcul pratique de l'équation du pendule simple inversé dite de Winter. 2016 [Available from: http://adaposturologie.fr/Programme_Bernard.pdf.

16. Belyaev V. Film of a seven minutes stabilometric recording 2017 [Available from: http://ada-posturologie.fr/signal.htm.

17. Lejars F. Les veines de la plante du pied. Archives de Physiologie. 1890;5. pages

18. Bourceret. Circulation locale. Procédé d'injection des veines. Note présentée à l'Académie des Sciences 1885.

19. A.F.P. Normes 85: ADAP; 1985.

20. Usachev V, Belyaev V, Kononov A, Gagey P. The SKG area is not an informative parameter of stability. Man. Ther., Posturology Rehabil. J. In press. 